\title{
POR UMA DEFINIÇÃO DE TERCEIRIZAÇÃO
}

\author{
Paula Marcelino* \\ Sávio Cavalcante**
}

\begin{abstract}
O leitor tem em mãos um texto cujo objetivo principal é propor uma definição de terceirização que seja, ao mesmo tempo, rigorosa do ponto de vista analítico e útil do ponto de vista político. Defenderemos que a terceirização é todo processo de contratação de trabalhadores por empresa interposta, cujo objetivo último é a redução de custos com a força de trabalho e (ou) a externalização dos conflitos trabalhistas. Se a formulação parece e é simples, de maneira alguma ela é consensual. Tal como veremos ao longo do texto, a terceirização é objeto de estudo de várias disciplinas e, dentro de cada uma delas, muitas são as controvérsias em torno da sua definição. Este texto é resultado de ampla pesquisa bibliográfica e de estudos de casos específicos realizados pelos autores ao longo de suas pesquisas de pós-graduação.

PALAVRAS-CHAVE: terceirização, subcontratação, trabalho.
\end{abstract}

\section{INTRODUÇÃO}

Nos últimos vinte anos, os diversos ramos dos estudos sobre trabalho no Brasil deram origem a uma profícua produção sobre o tema da terceirização no processo de reestruturação capitalista. Contudo é preciso ressaltar que a profusão de pesquisas não foi acompanhada por uma definição conceitual precisa, viabilizadora de um consenso a respeito do que, em última instância, caracteriza o que se costumou chamar de terceirização. ${ }^{1}$ A proposta deste artigo é problematizar as análises existentes para, então, propor uma alternativa de definição.

Nas Ciências Sociais, encontram-se dezenas de dissertações, teses e pesquisas coletivas com o

* Doutora em Ciências Sociais. Professora do Departamento de Sociologia da Universidade de São Paulo (USP).

Avenida Professor Luciano Gualberto, 403 / 315, Departamento de Sociologia. Cidade Universitária. Cep: 05508900 - São Paulo, SP - Brasil. prpmarcelino@gmail.com

* Doutor em Sociologia pela Universidade Estadual de Campinas (IFCH/Unicamp). saviomc@gmail.com

${ }^{1}$ Falta de consenso que, por certo, é expressão da diversidade teórica e metodológica das ciências sociais. Contudo, para o campo crítico, uma concepção de fundo minimamente compartilhada auxiliaria, no nosso entendimento, a compreensão das determinações mais essenciais do processo. intuito de analisar as mudanças da organização do trabalho no país, nas quais é visivelmente destacado o forte impacto causado pelo crescimento da terceirização nos mais variados ramos produtivos e suas consequências no que se refere à ação dos sindicatos e à precarização das condições de trabalho. Essa produção acadêmica organizou-se a partir, principalmente, do início da década de 1990. Assim, entre fins dos anos 1980 e começo dos 1990 - momento em que as reestruturações se consolidam e avançam fortemente pelo país ${ }^{2}$-, já havia importantes estudos de caso e pesquisas sobre essas transformações, o que acabou por construir um campo variado de debate sobre o tema.

Um marco da bibliografia do período foi a coletânea de artigos organizada por Ramalho e Martins, Terceirização: diversidade e negociação no mundo do trabalho, publicada em 1994, que continha colaborações de cientistas sociais e sindicalistas. As várias teses e propostas ali presentes reuniram importantes análises do período

${ }^{2}$ Processo discutido com enfoques diversos por autores como
Antunes (2006), Braga (1996), Hirata (1993), Leite (1994), Teixeira e Oliveira (1998). 
e acabaram por servir de base para muito do que foi desenvolvido nos anos posteriores. ${ }^{3}$ Passados quinze anos, uma nova coletânea com artigos de pesquisadores e sindicalistas foi lançada por Dau, Rodrigues e Conceição (2009). O livro nos permite visualizar que, nesse período, muito se produziu na tentativa de compreensão das mudanças nas relações de trabalho no país, assim como também passaram os sindicatos a expor com mais experiência o diagnóstico das situações enfrentadas pelos trabalhadores e os prováveis caminhos que a luta sindical terá de trilhar. O nome da coletânea é bastante emblemático: Terceirização no Brasil: do discurso da inovação à precarização do trabalho (atualização do debate e perspectivas).

Um dos pontos que parecem ser mais consensuais é a constatação, por esse conjunto de analistas, de que a terceirização modificou de forma estrutural o conjunto da base produtiva e de serviços no país, nas últimas duas décadas. Os modelos organizacionais, pautados pela produção "flexível" e "enxuta", muitos derivados da experiência japonesa, criaram formatos de empresa e tipos de contrato de trabalho de natureza distinta daqueles que vigoravam na tradicional empresa fordista do século XX: contratos de trabalho com jornada em tempo integral e com as garantias legais asseguradas, no caso do Brasil, pela Consolidação das Leis Trabalhistas (CLT). Nessas duas décadas em que a terceirização alterou estruturalmente o mercado de trabalho, empresas e trabalhadores passaram a se relacionar em condições econômicas, políticas e sociais significativamente distintas. Essa mudança estrutural do mercado de trabalho se verifica, por exemplo, no rebaixamento geral das condições de trabalho e emprego das categorias terceirizadas ${ }^{4}$ e no peso que a ameaça de terceirização tem nas negociações daqueles trabalhadores não terceirizados.

${ }^{3}$ Como prova da importância desse livro naquele contexto, basta lembrar que ele foi publicado no ano seguinte à entrada em vigor da Súmula 331 do TST, que é ainda hoje a orientação dos tribunais para julgar questões relativas à terceirização.

${ }^{4}$ Apenas para dar um exemplo do que estamos chamando de reestruturação do mercado de trabalho, ao comparar os acordos coletivos de trabalhadores petroleiros e trabalhadores terceirizados na refinaria de Paulínia (SP), Marcelino (2012) conclui que a situação de trabalho dos petroleiros é
Outra constatação frequente, ainda que relativizada em certas análises, diz respeito aos resultados desse processo do ponto de vista dos trabalhadores. Trata-se da tendência de precarização das condições de trabalho com o advento das terceirizações, o que se evidencia em perda salarial e de direitos, aumento da intensidade do trabalho e dos riscos à saúde do trabalhador, além de dificuldades enfrentadas pelos sindicatos para unificar as lutas comuns. É possível afirmar, então, que a terceirização é a principal forma de precarização do trabalho nas últimas duas décadas (Druck, 2011).

Entretanto, a despeito dessas preocupações compartilhadas por diversas pesquisas, podemos ainda perceber uma dificuldade de definição do termo terceirização, o que se relaciona, segundo sustentamos, a uma dificuldade em caracterizar o lugar ocupado pela terceirização na fase de reestruturação neoliberal do capitalismo. Ainda que possam ser feitas analogias da terceirização com práticas antigas, existentes desde os primórdios do capitalismo, neste artigo, procuramos entender essa prática como fenômeno particular do capitalismo contemporâneo articulado à hegemonia das finanças. Propomos diferenciar termos que costumam aparecer como sinônimos no debate (terceirização, subcontratação e externalização), o que permite construir uma alternativa de definição com consequências analíticas e políticas importantes.

\section{O DILEMA DA DUALIDADE}

Segundo Leiria e Saratt (1995), o criador do termo "terceirização" foi Aldo Sani, engenheiro e diretor superintendente da Riocell - empresa de celulose de Guaíba (RS) - no início da década de 1970. A palavra "terceirização" é um neologismo; sua origem é o latim terciariu, derivada do

amplamente mais regulada pelo instrumento da negociação coletiva que a dos terceirizados. Dos 39 itens aplicáveis às duas categorias - referentes a benefícios, segurança no trabalho e condições de contrato - 24 constam apenas no acordo coletivo dos petroleiros. 
ordinal tertiariu. Ao que tudo indica, esse neologismo é uma exclusividade brasileira; em todos os outros países, o termo usado refere-se à relação entre as duas empresas, ou seja, é sempre a tradução da palavra subcontratação: em francês, soustraitance, em italiano, sobcontrattazione, em espanhol subcontratación, no inglês, outsourcing, em Portugal, subcontratação.

Principalmente durante os anos de 1990, várias publicações da área de Administração foram lançadas e consistiam, em sua grande maioria, em manuais sobre como implementar o chamado "mecanismo de gestão", ou "técnica moderna de administração". Em sua quase totalidade, defendia-se a ideia de que as empresas deveriam focar suas "atividades-fim" e delegar tarefas e processos acessórios ("atividades-meio") a outras empresas especializadas. O tom fortemente pragmático desse discurso em direção aos benefícios para as empresas tem como pano de fundo uma vaga ideia das noções de modernidade e globalização. Nessa bibliografia, a palavra modernidade é usada no sentido dado pelo senso comum: a inovação constante, tanto do ponto de vista técnico quanto do organizacional. Nessa acepção de modernidade, só há positividade; posicionar-se contra qualquer iniciativa "modernizadora" significa, portanto, contrariar os princípios da lógica. Quanto ao termo globalização, seu emprego tambémé vago, sem muito rigor conceitual. De uma maneira geral, tratam-no como uma palavra neutra, cuja positividade ou negatividade é definida pelo evento que se analisa. ${ }^{5}$

Ainda que notadamente distintos das abordagens "empresariais", alguns valores e percepções desse "pano de fundo" conceitual podem ser encontrados nos debates que tomaram conta de outros ambientes acadêmicos e sindicais. Apresentado sob formas diferentes, o essencial do argumento pode ser assim formulado: dadas as condições básicas de funcionamento de qualquer economia capitalista e da produção complexa em larga escala, em um contexto de globalização, as empresas tenderão a buscar serviços cada vez mais

${ }^{5}$ Exemplos de trabalhos com essas características são os de Leiria et al. (1992) e Oliveira (1994). especializados para incremento da sua produtividade e da "qualidade" dos seus produtos. Elas passam, assim, a subcontratar força de trabalho, deixando de ser responsáveis, diretamente, por parte da produção ou dos serviços a ela ligados. Essas relações seriam baseadas na cooperação entre empresas e seriam simétricas, sem necessariamente existir a subordinação de uma em relação à outra. Porém, como toda empresa capitalista precisa sobreviver no mercado, algumas acabam se valendo do artifício das subcontratações para simplesmente reduzir seus custos, com pouca ou nenhuma preocupação sobre como e em que condições esse trabalho subcontratado será desempenhado. Assim, ao invés de o resultado ser a proliferação de empresas "modernas" e pautadas pela qualidade do processo produtivo, criam-se várias formas de burla à legislação trabalhista, o que faz aumentar a precarização do trabalho.

Diversas pesquisas empíricas orientaram-se por esse raciocínio. Ao apresentarem casos específicos da realidade brasileira, os estudos encontravam consequências negativas para os trabalhadores e para os sindicatos. Entretanto, em muitos desses trabalhos, quando apontavam críticas à terceirização, estava subentendido que era apenas àquelas formas consideradas distorcidas - sobretudo devido a questões culturais do país - de uma tendência mundial que pode, se bem aplicada, acarretar melhorias ao processo produtivo ao criar redes especializadas nas quais se encontram trabalhos mais criativos e autônomos. Algo semelhante, por exemplo, à situação analisada por M. Piore e C. Sabel (1984) de "especialização flexível". A ideia subjacente dessas visões é a de que a crescente "modernização" das relações de trabalho no país diminuiria os aspectos "negativos" da terceirização.

Dava-se forma ao que muitos chamavam de "as duas modalidades de terceirização". Um exemplo claro é visto no artigo de Abreu e Sorj (1994, p.64) sobre formas distintas de subcontratação:

A primeira [modalidade de subcontratação] [...] envolve uma terceirização da produção motivada pelas necessidades de alcançar níveis de qualidade e produtividade superiores. As inovações tecnológicas e de gestão da produção obtidas ao 
nível da empresa subcontratante são transferidas para as empresas subcontratadas. O segundo caso que pode ser chamado de "terceirização por contingência” significa a externalização da produção como mecanismo de redução de custos de produção. Transferir para o trabalhador os custos de energia, equipamento e espaço e apoiar-se numa força de trabalho sem o ônus da legislação trabalhista são as motivações principais da subcontratação no segundo modelo.

Na mesma coletânea, Faria (1994) utiliza uma lógica de análise semelhante. A primeira modalidade de terceirização seria aquela que vem "dos países industrializados", chamada, segundo o autor, de outsourcing total, que gira em torno da busca do aumento de produtividade e qualidade a partir de um novo "posicionamento comportamental”, o "ganha-ganha”, baseado na parceria e satisfação das partes. Para a segunda modalidade, no entanto, ele dá outro nome - por sinal, recorrente em análises subseqüentes : "outsourcing tupiniquim”, isto é, a terceirização predominante para o "gosto do atrasado empresarial brasileiro", na qual o objetivo é a obtenção de lucros em curto prazo, reduzindo-se custos de forma generalizada. Somente essa última levaria a uma situação de antagonismo entre os interesses empresariais e os trabalhadores e sindicatos.

Ainda na década de 1990, uma proposta diferente de compreensão foi apresentada por Druck (1999). Sem desconsiderar a diversidade das experiências realizadas no país, a autora negava a possibilidade de se separar o que seria uma técnica "moderna” e uma versão "à brasileira”. O argumento, em sentido metodológico e teórico, dizia respeito à impossibilidade de se analisar o processo pela identificação de formas ideais contrastando com práticas distorcidas. Em sua opinião, a terceirização precisava ser vista como uma estratégia inclusa num programa maior de reestruturação produtiva. Tal programa visava, sobretudo, a novas fontes de acumulação de capital e ao contorno das barreiras a essa acumulação criadas pelos custos da força de trabalho e pelas resistências dos trabalhadores. Para Druck, ao se postular uma suposta "terceirização à brasileira”, ignorava-se um complexo movimento eco- nômico e político que atingia todos os países do mundo. Assim,

\begin{abstract}
Não há como contrapor "redução de custos" versus "qualidade, produtividade, competitividade", pois, para se atingirem os novos padrões de competitividade, exigidos pela reordenação do mercado internacional, o "tripé" custos, qualidade e produtividade é o principal sustentáculo não somente da terceirização, mas do modelo japonês no seu conjunto; até porque o processo de melhoria de qualidade significa, geralmente, redução de custos (Druck, 1999, p.149).
\end{abstract}

A referência ao "modelo japonês" se explica pelo fato de as inovações da indústria daquele país, principalmente na Toyota, terem influenciado significativamente projetos de reestruturação em várias empresas de outras partes do mundo, isto é, serviram de base a muito do que se projetava como moderno. A questão era justamente mostrar que não havia tal dualidade para esse projeto. Como já havia ressaltado Chesnais (1996, p.53), para os grandes grupos japoneses, o objetivo das transferências de atividades para redes de subcontratação foi o de fazer "[...] recair sobre firmas 'terceiras' os imprevistos conjunturais e para impor aos assalariados dessas firmas o peso da precariedade contratual, combinado com níveis de salariais bem inferiores."

Na década de 2000, uma nova proposta de análise foi construída por Ruduit-Garcia (2002). Para o autor, seria preciso superar teses que visavam, a priori, concluir se a terceirização é positiva ou negativa. $\mathrm{O}$ argumento principal por ele desenvolvido é de que as relações entre empresas são multiformes e não tendem, necessariamente, a um ou outro lado. Ao tomar como exemplo seu estudo no setor de telecomunicações, RuduitGarcia conclui que, se a empresa central estabelece vínculos baseados em estratégias competitivas, de cooperação, sobre produtos técnicos mais complexos, haverá melhores condições para existência de formas estáveis e não precárias de emprego. Porém, se a relação é de subordinação e as intenções somente giram em torno da redução de custos, os contratos de trabalho geralmente têm sido precári- 
os. O autor afirma que “[...] quanto mais próxima da empresa central estiver a empresa contratada, maiores seriam as chances de práticas não precárias de emprego" (Ruduit-Garcia, 2002, p.422).

Ainda com base nessas observações, ao construir os verbetes sobre subcontratação e terceirização em Catani e Holzmann (2006), Ruduit-Garcia busca diferenciar os dois termos. Subcontratação seria um termo genérico para toda transferência de atividades e tarefas de uma empresa a outra unidade empresarial, o que pode se referir tanto à atividade-fim de uma empresa quanto a atividades de suporte ou de apoio. As modalidades de subcontratação seriam diversas: trabalho em domicílio, cooperativas, autônomo, por empreitada, franquias, teletrabalho, por projetos etc. Já a terceirização expressaria

[...] o recurso gerencial pelo qual uma empresa transfere parte de sua atividade-fim - industrial, de serviços ou agrícola - para outra unidade empresarial, tendo em vista flexibilizar a organização e as relações de trabalho e focar esforços em atividades com mais especialização e maior valor agregado (Ruduit-Garcia, 2006, p. 311).

A terceirização seria, assim, um "[...] método gerencial que se distingue das antigas práticas de subcontratação, posto que busca instituir organizações horizontais” (2006, p.311).

A questão principal é que, no tocante tanto ao que Ruduit-Garcia considera ser subcontratação quanto terceirização, não seria possível, segundo o autor, entender o processo de forma única, pois o fenômeno seria diverso, e cada modalidade comportaria consequências distintas aos trabalhadores. Assim, “[...] a subcontratação não se limita necessariamente a práticas precárias de trabalho" (2006, p.276), e a terceirização poderia também significar oportunidades para pequenas empresas terem acesso a capital e a novos mercados, o que levaria a uma maior capacitação de empresas e trabalhadores. Os resultados de cada processo dependeriam de como os "atores" interagem em cada local, de acordo com especificidades sociais e econômicas.

Estudando a ação sindical diante da terceirização em dois grandes sindicatos da re- gião de Campinas (SP), Marcelino (2008) buscou uma definição de terceirização - aquela que defenderemos neste trabalho - que combina elementos dos trabalhos de Druck e Ruduit-Garcia. De um lado, tal definição incorpora a inexistência de uma dualidade entre terceirização e precarização do trabalho advindas de "boas" ou "más" terceirizações, tal como nos aponta Druck. De outro, essa definição de terceirização converge com a de Ruduit-Garcia, quando afirma que nem toda subcontratação é, necessariamente, terceirização. Mas, em nossa leitura, ao tentar superar o dualismo de visões necessariamente “positivas" ou "negativas", Ruduit-Garcia acaba por construir outro, segundo o qual o processo, por depender de inúmeros fatores e da interação de diversos "atores sociais", pode ser tanto uma coisa quanto outra, livre de determinações sociais mais gerais. Mesmo que recolocada, a insuficiência da definição de Ruduit-Garcia nos parece ser uma variação daquela posição já identificada e criticada por Druck (1999), qual seja, a de que seria possível, de acordo com as posturas tomadas entre as empresas, estipular processos estratégicos voltados mais para a busca de qualidade e eficiência, por um lado, e tentativas mais explícitas de redução de custos, por outro.

Numa tentativa de superação desses limites, consideramos que é possível traçar certas tendências gerais da acumulação capitalista que irão fundamentar qualquer processo de reestruturação produtiva. Não se trata de um a priori arbitrário, mas do próprio movimento econômico e político que é, em última instância, o que condiciona as variações existentes. Em segundo lugar, ainda que concordemos que é necessário encontrar diferenças entre subcontratação e terceirização, os critérios de atividades auxiliares ou atividades-meio e atividades-fim não tem como servir a esse propósito. Voltaremos a esse ponto ao fim do artigo, mas seria preciso já resgatar uma questão fundamental: foram os empresários, nas décadas de 1980 e início de 1990, que buscaram legitimar as terceirizações a partir do argumento de que, subcontratando atividades-meio, as empresas poderiam ficar mais bem 
focadas em suas finalidades. A Súmula 331 do TST, de fato, incorporou esse ideário. Porém, na atualidade, é do próprio setor empresarial que surgem reivindicações para a legalização da "terceirização total", até para atividades-fim (Conceição; Lima, 2009). Na área do Direito, também cresce o questionamento sobre a indefinição do que seria cada tipo de atividade. Isso nos parece um bom indicativo de que o critério que considera “meios" e fins", para essa dimensão mais teórica da análise da subcontratação ou terceirização, é fluido e limitador do alcance de análise. ${ }^{6}$

Se, por um lado, discordamos da divisão feita por Ruduit-Garcia entre boas e más terceirizações, por outro, concordamos com o autor no sentido preciso de que somente com a compreensão das relações concretas estabelecidas entre empresas e trabalhadores é possível extrair um entendimento do processo de terceirização. Isto é, independentemente do que queriam os idealizadores do "modelo japonês" ou se existe ou não uma dualidade entre formas de terceirização, caberia às análises (acadêmicas ou não) pesquisar as tendências e os rumos tomados pelos programas de reestruturação produtiva e, por conseguinte, pelas terceirizações. Dito de outro modo, caberia apresentar dados empíricos, estudos de caso e de setores econômicos que pudessem indicar as reais condições de trabalho nas empresas que compunham as redes de subcontratação e terceirização. Estariam elas realmente se especializando em atividades mais complexas e diferenciadas, preservando direitos trabalhistas das categorias e aumentando o dinamismo das economias nacionais? Ou seriam as terceirizações as melhores formas encontradas para quebrar resistências e diminuir os custos gerais com a força de trabalho, por meio de diminuição de salários, perda de direitos e piora das condições de trabalho?

Não há condições, neste espaço, de proporcionar um levantamento sobre a totalidade do que foi até aqui produzido em termos de consequências da terceirização para as condições de emprego e

${ }^{6} \mathrm{O}$ que não significa que, nas disputas políticas presenciadas no poder judiciário e no legislativo, a distinção entre atividade-meio e atividade-fim não possa ter um papel importante para a luta defensiva dos trabalhadores. trabalho. ${ }^{7}$ Contudo, é possível dizer, com boa segurança, que a grande maioria das pesquisas revelou claros indícios que comprovam a segunda tendência, isto é, de que as terceirizações levam à precarização (em maior ou menor grau) das relações de trabalho e emprego. Segundo Druck (2011), dado o acúmulo de pesquisas feitas nas últimas duas décadas, constata-se que a terceirização causou efetivamente a precarização das condições de trabalho no Brasil. Na verdade, seria interessante mudar a própria pergunta: nos casos em que é possível comparar situações anteriores de enquadramento ocupacional e resultados posteriores devidos a processos de terceirização, houve, em algum lugar do país, melhoria das condições de trabalho e emprego (salários, direitos, segurança e vínculos sindicais) em relação às condições anteriores? Até o presente momento, desconhecemos casos em que a resposta a essa pergunta seja positiva.

\section{TERCEIRIZAÇÃO E DIVISÃO DO TRABALHO}

Os estudos de caso e os relatos dos sindicatos da coletânea de artigos de Dau, Rodrigues e Conceição (2009, p.1) também indicam que a resposta à pergunta acima é, de fato, negativa. Para os organizadores, “[...] a terceirização, além de ter piorado as condições do emprego, aumentado o trabalho precário e informal-sempre ressalvadas as exceções -, contribuiu também para promover uma espécie de polarização entre os assalariados". Polarização estabelecida entre um núcleo relativamente estável de trabalhadores e a zona cada vez mais expandida de trabalhadores que são submetidos a formas precárias de emprego e trabalho.

Mas, ao longo das intervenções da citada coletânea e em várias outras produções contemporâneas, não se encontram esforços conceituais explícitos para definir terceirização e para especifi-

\footnotetext{
7 Poderíamos, contudo, citar alguns exemplos, como Marcelino (2004) na indústria metalúrgica e Marcelino (2008 e 2012) na Petrobras e no serviço público dentro da universidade; Druck (1999) e Godinho (2003) sobre a indústria Petroquímica, Amorim (2011), Colli (2000), Jinkings e Amorim (2006) sobre a indústria têxtil; Cavalcante (2009 e 2010) sobre o setor de telecomunicações.
} 
car o lugar dela no processo de reestruturação do mercado de trabalho no Brasil. ${ }^{8}$ A regra é que o termo terceirização seja usado como sinônimo de subcontratação (terceirizados podem ser assalariados de empresas interpostas ou indivíduos em tarefas informais) e que, do ponto de vista de sua origem, seja tratado como um desdobramento natural da divisão de trabalho no capitalismo.

Um importante aspecto no sentido de uma definição de terceirização é colocado por Marcelino (2008) e Silva (2009); trata-se das consequências jurídicas dos contratos de terceirização. A relação entre empresa e trabalhador é regulada pelo Direito do Trabalho. Com a terceirização, essa mesma empresa, agora tomadora, se livra das regras dessa área do Direito - tradicionalmente mais restritivas, pois protetoras do trabalhador - e passa a administrar contratos com outras empresas na esfera do Direito Civil. ${ }^{9}$ Esse é, portanto, o objetivo das empresas, isto é, tentar escapar do enquadramento jurídico trabalhista, o que não significa, evidentemente, que a Justiça do Trabalho não possa identificar relação de emprego independentemente das intenções das partes envolvidas.

Os argumentos de Young e de Ypeij, que são resumidos em Araújo e Ferreira (2009), também buscam conceituar modalidades distintas de terceirização. Yepij faz uma distinção análoga àquelas aqui apresentadas anteriormente entre formas de subcontratação parcial, completa, simétrica ou assimétrica. Já Young diferencia os conceitos de outsourcing e de subcontracting. O primeiro, traduzido como terceirização, estaria ligado a transferências de atividades produtivas e de serviços

${ }^{8}$ Encontramos esse esforço em Pochmann (2007) e nos trabalho publicados por Druck e Franco (2007) e Druck (2011).

${ }^{9}$ Segundo Martins (2005, p.53-54), os principais contratos de natureza civil aplicados aos processos de terceirização são a empreitada e a subempreitada, a prestação de serviços e a parceria. A empreitada - ou locação da obra - distingue-se da locação de serviços pelo fato de, na primeira, contratar-se um resultado e, na segunda, uma atividade, embora haja em ambas, a princípio, independência e autonomia na prestação de serviços. Na empreitada, o empreiteiro pode ser pessoa física ou jurídica, mas o empregado só pode ser pessoa física (art. 3o da CLT). No contrato de trabalho desse empregado, não consta o resultado, mas a atividade; o empreiteiro é autônomo para gerenciar esse trabalho. de uma empresa para uma terceira, a qual assumiria responsabilidade de execução sob determinadas condições contratuais. A empresa terceira pode estar dentro ou fora da contratante, mas o que importa é que seus empregados estão em condições diferenciadas de trabalho. Já a subcontratação consistiria nas relações entre empresas em que há contratação de fornecedores de produtos ou serviços completos. Esse aspecto da análise de Young reaparecerá em nossa discussão a seguir. Seria essa subcontratação de "fornecedores de produtos e serviços completos" nada mais do que a divisão do trabalho entre empresas capitalistas? Seria correto continuar a chamar esse processo de "subcontratação"?

A mesma questão reaparece ainda mais explícita no artigo de Conceição e Lima (2009). Ao discutirem as reivindicações atuais de organizações patronais e sindicatos a respeito de uma nova legislação referente à terceirização no país, afirmam que a terceirização não é uma novidade, pois está presente desde os primórdios da Revolução Industrial no sistema de putting-out. De forma que:

[...] de uma maneira abrangente, pode-se afirmar que o ato de terceirizar é indissociável do próprio processo de divisão social do trabalho. Em qualquer sistema econômico baseado na divisão social do trabalho - seja ele capitalista ou não - a terceirização será elemento constitutivo, já que a divisão do trabalho resulta sempre em especialização e troca (Conceição; Lima, 2009, p.188).

Mas, segundo Conceição e Lima (2009), por ser difundida em meio à abertura de mercados vinda com a globalização, vê-se a emergência de aspectos negativos no Brasil, ou seja, num contexto de concorrência intensa, as empresas buscam aumentar flexibilidade e causam sérios prejuízos aos trabalhadores.

Dessa maneira, percebe-se que, a despeito de certos consensos sobre o tema, persistem indefinições sobre as relações entre subcontratação, terceirização e a própria divisão do trabalho capitalista. E essa lacuna não é um mero detalhe. Afinal, se terceirização for sinônimo de subcontratação 
e consistir, em última instância, na especialização inerente à divisão do trabalho capitalista, teria sentido - teórico, mas também político - questionar se ela gera necessariamente redução de custos e precarização do trabalho? Seria possível conceituar o lugar que a terceirização ocupa nas relações de trabalho no país?

A seguir, buscamos mostrar que a terceirização é uma das formas de subcontratação e que ela não pode ser confundida com a divisão capitalista do trabalho em si.

\section{UMA PROPOSTA DE DEFINIÇÃO: O critério da intermediação da força de trabalho ${ }^{10}$}

Nossa definição parte do pressuposto de que a terceirização, no Brasil, tem um lugar preciso na estrutura do mercado de trabalho: nos últimos vinte anos de nossa história, ela se tornou o mais importante recurso estratégico das empresas para gestão e redução dos custos com a força de trabalho. Assim, para sermos rigorosos com a amplitude da utilização do termo terceirização e por reconhecer a importância política que ela tem para a organização dos trabalhadores, optamos por uma definição abrangente: terceirização é todo processo de contratação de trabalhadores por empresa interposta, cujo objetivo último é a redução de custos com a força de trabalho e/ou a externalização dos conflitos trabalhistas. Ou seja, é a relação na qual o trabalho é realizado para uma empresa, mas contratado de maneira imediata por outra. Na realidade brasileira, a terceirização é inseparável da ampliação da exploração do trabalho, da precarização das condições de vida das classes trabalhadoras. E, certamente, ela não teria a abrangência que tem hoje se não fosse a sua capacidade de reduzir custos - e, portanto, de servir como poderoso instrumento para a recomposição das taxas de lucro - e de transferir para outras empresas (as contratadas) o "problema trabalhista”, a necessidade de administração da força de

${ }^{10}$ Algumas das ideias presentes nesse item foram inicialmente trabalhadas em Marcelino (2007). trabalho e de negociação com ela e seus sindicatos. É esta definição ampla que defenderemos aqui.

Quando dizemos que terceirização é todo processo de contratação de trabalhadores por empresas interpostas, há uma clara opção por privilegiar a relação empregatícia estabelecida por essa forma de gestão da força de trabalho. Isso porque é na natureza dos contratos firmados entre as empresas e os trabalhadores que encontramos o que há de mais estável nessas relações. Todo o resto é fluido: a definição de atividadefim e atividade-meio, ${ }^{11}$ a real capacidade técnica das empresas subcontratadas, a noção de parceria, a ideia de que a terceirização garante qualidade. E, quando falamos de relação empregatícia, não estamos nos referindo ao tipo de contrato que o trabalhador estabelece (temporário ou por tempo indeterminado) nem às condições de remuneração e proteção desse trabalho (presença de mais ou menos direitos trabalhistas, maior ou menor salário). Referimo-nos, sim, ao fato de que, entre o trabalhador e a atividade que ele desenvolve para benefício da produção ou do serviço de uma empresa, há outra empresa, cujos recursos provêm da primeira (mesmo que a empresa terceira seja contratada por mais de uma tomadora) e os lucros são auferidos a partir da intermediação da força de trabalho. Nessa relação, importa pouco, portanto, se a empresa terceirizada tem ou não maior capacidade técnica que a contratante.

Entendemos que a atividade-fim de qualquer empresa capitalista é a valorização e realização do valor; algumas, para tanto, produzem mer-

${ }^{11}$ Klein (2006) entende que o branding (gestão da marca) tornou-se o grande objetivo de empresas de todo os segmentos. Para tanto, busca-se construir uma identificação dos consumidores com os valores que as marcas representariam. A consequência dessa conexão direta entre consumidores e valores simbolizados pelas marcas é o fato de a produção física das mercadorias passar a ser vista como externa ao "negócio" dessas marcas. Com esse intuito, os discursos de gerentes e acionistas tentam fazer crer que se tornou obsoleta a ideia segundo a qual uma empresa é responsável pela sua força de trabalho. Ou seja, toda atividade produtiva passa a ser "terceirizável". Nos termos que aqui estamos tratando, significa dizer que, do ponto de vista das empresas (ou marcas), se existe uma atividade-fim, ela tem muito pouco a ver com qualquer tipo de trabalho vivo que essa empresa demande. Não é esse o negócio delas. Alguns exemplos já são bem conhecidos: Nike, Benetton etc. assim como o caso da Levi's no Brasil (Amorim, 2011). 
cadorias tangíveis, outras prestam serviços ou investem em mercado financeiro etc. $\mathrm{O}$ resultado concreto do trabalho importa na medida em que cristaliza o processo de valorização em determinada mercadoria, mas não é suficiente para determinar, de maneira fixa e rígida, o que é atividade-fim ou atividade-meio. Na verdade, ao focar no processo de trabalho, a discussão sobre atividade-meio e atividade-fim acaba por se referir a valores de uso e, assim, inverte a relação de determinação da lógica capitalista: o processo de valorização aparece como subordinado ao processo de trabalho, quando é o inverso que guia a ação das empresas, isto é, é a valorização que subsume o processo de trabalho.

Assim, distanciamo-nos de duas acepções comuns nos debates sobre terceirização aqui citados. A primeira é aquela que afirma ser possível analisar a terceirização pelo prisma da atividade que vem a ser terceirizada, o que leva a discussões sobre a existência ou não de "parcerias" ou "competência técnica". Não se trata de requentar, aqui, o argumento da "terceirização tupiniquim". Mas é preciso reconhecer que boa parte das empresas terceiras, no país, não é criada porque tem especialização técnica. Pelo contrário, são empresas que passam a se especializar a partir da transferência de tecnologias e de conhecimento da tomadora para a terceira, o que comprova a subordinação estrutural ${ }^{12}$ desta àquela. Em alguns setores, foi um fenômeno comum a existência de empresas fundadas por antigos trabalhadores das empresas principais, em processos individuais ou coletivos (as cooperativas, por exemplo). Outras tantas surgem meteoricamente por ocasião de editais públicos e desaparecem na mesma velocidade (vide caso das "gatas" nas refinarias brasileiras). Em outras palavras, uma definição de terceirização não pode basear-se na especialização da terceira. Certamente, como tendência geral, esse não é o fator determinante para se subcontratar trabalhadores no Brasil.

A segunda acepção da qual nos distanciamos é aquela que define terceirização somente se houver relação duradoura entre empresas, como,

${ }^{12}$ Sobre a subordinação estrutural na discussão jurídica, ver Delgado (2007). por exemplo, em Martins (2005). O contrato duradouro entre uma contratante e uma subcontratada é, na nossa compreensão, apenas um dos tipos de terceirização possível. Talvez ele seja menos precário do ponto de vista do trabalhador, pois tem mais chances de propiciar vínculos trabalhistas mais sólidos (com os direitos que um contrato por tempo indeterminado garante), de interferir na definição de acordos coletivos cumulativos e de propiciar maior organização no local de trabalho. Mas definir terceirização pela longevidade da relação entre duas empresas seria ignorar uma gama imensa de relações interempresariais que se verificam no contexto brasileiro como, por exemplo, as numerosas subcontratações realizadas pelas refinarias brasileiras para sua ampliação e manutenção (Marcelino, 2008, 2012).

Sobre essas diferentes formas de compreensão, cabe aqui um comentário em relação à maneira pela qual o Direito trata o processo. Dizer que a terceirização, tal como fazemos, é contratação de trabalhadores por empresas interpostas para reduzir custos poderia ser associado, no campo da discussão jurídica, à já antiga figura do marchandage, uma forma pejorativa de designar a simples "intermediação de mão de obra", que é considerada ilícita e também condenada pela Organização Internacional do Trabalho (OIT), por tratar o trabalho como uma simples mercadoria (Carelli, 2007). O problema é que, nessa dimensão do debate jurídico, volta-se ao modelo referente à "boa" e à "má" terceirização, ou à terceirização "correta" e à "falsa", pois, quando prevalece a "intermediação de mão de obra", enxergase seu caráter negativo, enquanto a contratação de empresas com alta especialização representaria sua face verdadeira ou positiva. Evidentemente, do ponto de vista jurídico crítico, faz todo o sentido lutar contra as formas mais abjetas e precárias de terceirização, nas quais nem um vestígio sequer de especialização pode ser encontrado. Porém não há processo de busca de especialização nessa fase atual do capitalismo que também não se paute pela redução de custos, isto é, que também não resulte numa tendência de precarização e quebra de resis- 
tência dos trabalhadores. Daí a necessidade teórica, mas também política, de se problematizar o que se chama de intermediação de mão de obra e encarar a terceirização de forma ampla.

Assim, de acordo com a definição que propomos, subcontratação e terceirização não são sinônimos. Terceirização é uma das formas de subcontratação; há outras, tais como: o repasse de tarefas pelo trabalho domiciliar, os trabalhadores autônomos etc. O que interessa reter aqui éo que vários autores (Morin, 2004; Carelli, 2002, 2003, entre outros) - ainda que a definição deles seja diferente da nossa - apontaram como externalização da contratação de trabalhadores. Toda vez que uma empresa resolve terceirizar, o que ela faz é transferir para outra os riscos e parte dos custos com a contratação da força de trabalho (os trabalhadores, os terceiros). Isso porque o seu próprio contrato deixa de ser trabalhista (empresa versus trabalhador) e passa a ser comercial ou civil (empresa versus empresa). Tal acontece se a empresa subcontratada é ou não especialista na função, se o contrato dela com seus trabalhadores é ou não por tempo indeterminado e se a relação entre contratante (ou tomadora) e subcontratada (ou terceira) é ou não duradoura.

A opção, neste texto, pelo uso da palavra terceirização, ao invés de subcontratação, se dá por vários motivos: a) esse é o termo consagrado no Brasil; b) é sobre ele que se constroem as ações públicas e se organizam trabalhadores e empresários em suas entidades classistas; c) toda a bibliografia sobre o tema está assentada nesse termo; d) o último e mais importante motivo: ele expressa com exatidão a ênfase que demos em nossa definição: a condição de terceiro do trabalhador no que é contratado entre duas empresas.

Diante da definição que propomos, não há como deixar de considerar parcela importante do trabalho temporário, tal como regulamentado pela Lei ${ }^{\circ} 6.019 / 74$, como uma forma de terceirização. Trabalho temporário, numa parte expressiva dos casos, é contratação de trabalhadores por empresa interposta. Nele, o trabalhador está vinculado a uma empresa, e quem paga seu salário, indiretamente, é outra, mesmo que o contrato de trabalho seja diferente dos chamados "terceirizados estáveis".

A gama do que pode ser chamado de terceirização é ampla e variada. Sem querer esgotar todas as relações possíveis entre duas empresas e trabalhadores terceirizados, cremos que uma lista do que é e do que não é terceirização pode clarear a definição dada, ou seja, pode exemplificá-la e explicá-la. Seguindo nossa definição, as principais formas de terceirização hoje, no Brasil, são:

a) Cooperativas de trabalhadores que prestam serviço para uma empresa contratante. Normalmente são ex-trabalhadores demitidos e incentivados a montar uma cooperativa. A cooperativa - que tem juridicamente status de empresa -é contratada pela empresa principal, e os seus trabalhadores passam a receber por produção - ou hora/ aula, no caso de cooperativas de professores em escolas e faculdades particulares.

b) Empresas externas, que pertencem a uma rede de fornecedores para uma empresa principal como, por exemplo, os fornecedores de autopeças para as montadoras, principal nicho desse tipo de terceirização. Possivelmente, é a forma de subcontratação mais organizada, menos precária e que sofre menos pressões contrárias à sua existência. É constituída por empresas de tamanho variado e, no caso das maiores, com participação de capitais multinacionais. Essa é uma forma de terceirização mais difícil de ser caracterizada como tal, devido à importância que as empresas de autopeças têm no mercado de trabalho brasileiro. Trata-se, entretanto, de uma cadeia ampla de trabalho subcontratado que converge para o produto final de uma ou mais empresas principais. No caso do setor automotivo, houve um processo posterior de transferência e (ou) externalização de setores da produção, mas, em larga escala, ele já nasceu estruturado em redes de subcontratação. Aqui, a terceirização em cascata é frequente.

c) Empresas externasà(s) contratante(s), subcontratadas para tarefas específicas, tais como as centrais de teleatendimento e construtoras.

d) Empresas de prestação de serviços internos à 
contratante: limpeza, manutenção, montagem, jardinagem, segurança, logística, recursos humanos etc. Essa é a forma clássica de terceirização, sobre a qual não pairam dúvidas da natureza das relações estabelecidas. São empresas contratadas, de maneira exclusiva ou não, de modo permanente ou não, para o desenvolvimento de atividades dentro da contratante. Esse tipo de terceirização acontece no setor produtivo e no de serviços, na iniciativa privada e nos serviços públicos, e pode estar presente tanto nas atividades consideradas secundárias quanto nas principais.

e) As chamadas Personalidades Jurídicas (PJs): são empreendimentos sem empregados, que passaram a realizar atividades que eram desenvolvidas por trabalhadores assalariados formais. Trata-se de uma forma de terceirização que tem ganhado importância no cenário brasileiro. Embora seja constituída por um trabalhador apenas, há uma empresa interposta (a dele), que faz diminuir sensivelmente os custos com a força de trabalho (a sua própria) e a carga tributária que recai sobre as contratantes. ${ }^{13}$

f) Quarteirização ou terceirização delegada, ou ainda terceirização em cascata. Em nossa opinião, o termo "terceirização em cascata" define melhor o processo e abarca várias possibilidades de subcontratação por empresas já subcontratadas. Tal processo é comum nas redes de subcontratação e nos processos de terceirização dentro das refinarias brasileiras, por exemplo (Marcelino, 2008). Se o objetivo da subcontratação é sempre a diminuição dos custos com a força de trabalho, é fácil imaginar as consequências da terceirização em cascata na precarização das condições de utilização e remuneração da força de trabalho.

Ainda segundo Martins, há a terceirização

${ }^{13}$ Mudar as formas de contratação altera significativamente os custos com a força de trabalho no Brasil. Contratar um autônomo ou uma cooperativa é bem mais barato que gerar um emprego interno. "Na comparação com o emprego assalariado formal (público ou privado), o peso da cunha fiscal no contrato PJ (empresa) chega a ser 56,5\% inferior, e o do autônomo de $11,7 \%$ inferior. Não foi por outro motivo que a explosão da abertura de novos negócios no Brasil se deu, em grande parte, devido ao surgimento das empresas sem a presença de empregados, modificando significativamente a natureza e composição dos custos de contratação dos trabalhadores." (Pochmann, 2007, p.15). por contratos mercantis, por exemplo: a) engineering: o objetivo desse tipo de terceirização é a obtenção de uma indústria construída, instalada e em funcionamento; b) contrato de fornecimento: ambas as partes pactuam a entrega de algum produto, sendo que o contrato cessa no momento dessa entrega; c) concessão mercantil: na qual um fabricante procura terceiros para ajudá-lo na comercialização de seus produtos e na prestação de serviços de assistência técnica; d) consórcio: pacto para a produção de bens ou serviços; e) assistência técnica: uma empresa treina outra para o fornecimento de assistência técnica de manutenção e conservação de seus produtos; f) representação comercial autônoma: o autônomo nunca pode ser pessoa jurídica; ele nunca é subordinado à direção do empregador.

Martins acredita que ofranchising-que foi traduzido para o português como franquia -é uma forma de se contratar terceiros para a prestação de serviços. Dele faz parte um conjunto de contratos mercantis que não possuem legislação específica. Em tese, o franqueado é independente e autônomo em relação ao franqueador, com pessoal e administração próprios. Na prática, as franqueadoras exercem um grande poder sobre os franqueados, delimitando sua forma de organização e interferindo sobre administração e o controle de pessoal. Como, para Martins, há formas corretas de terceirização e outras condenáveis, ele vê que a grande dificuldade, no franchising, é saber se o contrato não seria, na verdade, um contrato de trabalho; ou seja, é preciso verificar se a franquia é realmente lícita, ou se não representa uma forma de mascarar a relação de trabalho. A fixação de preço e a estimativa de lucros das mercadorias vendidas, determinadas pela franqueadora, podem evidenciar a ocorrência de um vínculo empregatício.

Segundo Krein (2007, p.154), na terceirização através dePJs, a relação de trabalho tambémé pautada por um contrato de natureza mercantil (ou comercial). Os custos da empresa contratante limitam-se ao pagamento e à gestão de um contrato comercial.

No esforço de compreender as formas que a terceirização assume no nosso país, devemos também dizer que tipo de relação entre trabalhador e 
empresa(s) não é terceirização. Aqui, de maneira ainda mais concreta, o critério de haver ou não uma empresa interposta na relação entre o trabalhador e a contratante é fundamental. Nesse sentido, não constituem casos de terceirização:

a) Trabalho domiciliar: se não há uma empresa ou uma cooperativa interposta entre os trabalhadores e a contratante, não há como definir o trabalho domiciliar como terceirização. Pode-se entendê-lo como subcontratação e como uma forma de precarização do trabalho bastante acentuada, em especial nos casos de trabalhadores do setor têxtil e de calçados, pagos de acordo com a produção. Mas não há uma relação de dupla subordinação (ordens e orientações da empresa subcontratada e financeira da contratante) que caracterize a relação de terceirização.

b) Trabalhador autônomo: essa é a condição de muitos trabalhadores em domicílio, mas também de vários outros que podem prestar serviços internos às empresas. Pode-se considerá-lo uma forma de assalariamento disfarçado, certamente uma forma de subcontratação, mas não terceirização. Os rendimentos desse trabalhador podem ser baixos, mas são pagos diretamente pela empresa contratante. A não ser que o trabalhador autônomo preste serviços para uma empresa que é subcontratada de outra, não é possível caracterizá-lo como terceirizado.

c) Joint ventures: tambémnão constituem terceirização, pois duas ou mais empresas se envolvem em igualdade de condições, partilhando interesses similares na operação que empreendem. Elas são sócias; uma não é subordinada à outra (Oliveira, 1994, p.68);

d) Não devem ser confundidos com terceirização também os processos de fornecimento de insumos e matérias-primas de uma empresa para outras. Aqui não há contratação de trabalhadores por empresa interposta, mas sim, um processo de produção cuja base de funcionamento é a divisão capitalista do trabalho entre empresas.

\section{CONSIDERAÇÕES FINAIS}

Fazer uma classificação da natureza da que fizemos acima não é tarefa simples, mesmo porque há um hibridismo nas relações entre empresas e trabalhadores, o que torna as fronteiras dos contratos de trabalho, por vezes, pouco claras. Por exemplo: caracterizar uma pessoa dona e única trabalhadora na sua própria empresa (PJ) como terceirizada e um autônomo como não terceirizado é quase uma questão puramente formal - o que faz bastante diferença nas consequências legais, mas pouca no que se refere às condições de trabalho. Outro exemploé o caso do pagamento por peça, no qual é comum que alguns trabalhadores repassem parte das tarefas para outros. Aqui também há uma relação de intermediação de força de trabalho, embora muito distinta da terceirização mais comum que descrevemos, com a presença de duas empresas. ${ }^{14}$

Outra dificuldade da definição que propomos é apontar a diferença entre a terceirização e a situação de simples transferências de insumos e matérias-primas de uma empresa a outra. A complexidade contemporânea da produção industrial e de serviços impede, por certo, um critério de separação puramente objetivo. A alternativa parece ser, em nossa visão, privilegiar a dimensão processual antes de uma tentativa de classificação técnica. Dito de outro modo, é preciso entender o processo pelo qual se desestrutura a norma de contratação formal rumo a novas estratégias de uso da força de trabalho, ou seja, como foi feita a "desverticalização" em cada setor ou em cada empresa. ${ }^{15}$ Também colabora para a identificação

${ }^{14}$ Parece-nos que essa dificuldade de delimitar claramente as relações é o motivo pelo qual, na França, há um esforço muito maior em mapear o que é o trabalho precário de maneira geral, do que em lutar contra essa ou aquela forma de contratação específica (terceirização, trabalho temporário, contratos subsidiados). Ver Marcelino (2008).

${ }^{15}$ Essa forma de análise contribui para entender, inclusive, os processos de "desterceirização". Estudos sobre a CSN apontam que houve precarização das condiç̃es de emprego e de trabalho tanto no momento de terceirizar quanto no de "desterceirizar" (Dias; Oliveira, 2011). Outro fato recente a ser lembrado foi a "reprimarização"; por empresas da construção civil. Segundo matéria de 9/ 06/2012 da Folha de São Paulo, várias construtoras diminuíram a quantidade de terceirizados em razão do crescimento econômico. É interessante notar que um dos motivos para evitar a terceirização, segundo os próprios empresários, foi a "perda de qualidade”. 
da terceirização e a compreensão de como ela se manifesta concretamente a chamada técnica do "feixe de indícios" apontada por Carelli (2003, p.91). Esse método consiste em constatar a existência de subordinação direta do trabalhador terceirizado à empresa tomadora através da combinação de uma série de fatores que, tomados isoladamente, não poderiam caracterizá-la. Tais elementos poderiam ser resumidos, segundo o autor, a três aspectos: gestão do trabalho pela tomadora de serviços, especialização da prestadora de serviços e prevalência do elemento humano no contrato de prestação de serviços. ${ }^{16}$

Assim, a ideia de "especialização flexível" de redes empresariais pode ser vista como a superfície de um processo muito mais abrangente, que carrega, em seu núcleo, uma tentativa de reduzir os custos da força de trabalho e (ou) externalizar os conflitos trabalhistas.

Nesse sentido, são importantes os dados levantados por Duménil e Lévy (2004). Os autores articulam as transformações da organização empresarial com movimentos econômicos relacionados à distribuição da renda entre as classes. Mostram que as mudanças gerenciais e o rebaixamento dos custos com a força de trabalho são aspectos de um projeto geral que visa a assegurar o poder e a renda das classes capitalistas, que foram ameaçados, de certa forma, pelos desequilíbrios e instabilidades dos anos 1970. É possível afirmar, assim, que as empresas são administradas de acordo com os preceitos da fase neoliberal do capitalismo; tanto as maiores elas mesmas grandes investidoras no mercado financeiro - quanto as menores.

Não se trata aqui de idealizar a produção fordista anterior, como se ela representasse um modelo supostamente correto de produção verticalizada ou um "trabalho decente" em face de uma precarização atual. Mas é preciso ter em consideração que, naquele contexto, havia fortes obstáculos (legais e políticos) impeditivos da

${ }^{16}$ Novamente, cabe a observação: na visão crítica do direito, usa-se o "feixe de indícios" para caracterizar uma terceirização "ilícita”, isto é, o que não é terceirização. Aqui, utilizamos o procedimento num sentido diferente, ou seja, com o intuito de auxiliar na compreensão do que é a terceirização no Brasil e seu lugar na reestruturação do mercado de trabalho. dissociação entre as empresas que comercializavam os produtos (produtos finais ao consumidor, ou insumos para as indústrias) e os trabalhadores que os fabricavam. Pretendemos chamar a atenção para um processo oposto: o da desvinculação do trabalhador com a empresa que lucra com a venda de produtos ou serviços criados por seu trabalho. Embora a "busca por especialização e qualidade" apareça em discursos e projetos, não é esse o elemento central que condiciona a ação das empresas.

Também não se trata de dizer que a única forma de subcontratação que leva à precarização do trabalho é a terceirização. Muito pelo contrário, poucas situações de trabalho são tão gritantemente precárias quanto aquelas adotadas pelas indústrias têxtil e calçadista com o trabalho por peça, por exemplo.

A definição de terceirização que propomos, com este texto, para os pesquisadores e ativistas brasileiros pode fazer avançar a precisão das análises sobre o tema. É certo que, do ponto de vista das lutas contra a precarização do trabalho, várias mediações precisam ser feitas entre a explicação teórica do processo e os mecanismos possíveis de oposição aos efeitos negativos da terceirização para os trabalhadores. ${ }^{17}$ Mas uma definição precisa de terceirização pode esclarecer os termos públicos da luta político-econômica que em torno desse fenômeno se estabelece, tanto no cotidiano da luta - organizada sindicalmente ou não - entre trabalhadores e empresários, quanto na disputa legislativa sobre o tema.

(Recebido para publicação em 04 de novembro de 2011) (Aceito em 09 de julho de 2012)

${ }^{17}$ São exemplos de tentativas para barrar os efeitos mais negativos da terceirização: a luta contra a terceirização de atividades-fim ou de atividades permanentemente necessárias ou essenciais, a tese jurídica da subordinação estrutural, uma nova regulamentação que garanta a isonomia de condições e o enquadramento sindical conjunto entre trabalhadores da tomadora e terceirizados. 


\section{REFERÊNCIAS}

ABREU, A.; SORJ, B. Subcontratação e trabalho a domicílio. In: MARTINS, Heloísa Helena Teixeira de Souza, RAMALHO, José Ricardo. (Org.) Terceirização: diversidade e negociação no mundo do trabalho. São Paulo: Hucitec, CEDI/NETS, 1994

ALVAREZ, Manuel S. B. Terceirização: parceria e qualidade. Rio de Janeiro: Ed. Campo, 1996.

AMORIM, Elaine Regina Aguiar. No limite da precarização? Terceirização e trabalho feminino na indústria de confecção. São Paulo: Ed. Annablume, 2011.

ANTUNES, Ricardo (Org.) Riqueza e miséria do trabalho no Brasil. São Paulo: Boitempo, 2006.

ARAÚJO, Angela Maria Carneiro; FERREIRA, Verônica Clemente. Terceirização e relações de gênero. In: DAU, Denise Motta; RODRIGUES, Iram Jácome; CONCEIÇÃO Jefferson José da. (Org.) Terceirização no Brasil: do discurso da inovação à precarização do trabalho (atualização do debate e perspectivas). São Paulo: Ed. Annablume, CUT, 2009. p.129-147.

BRAGA, Ruy. A restauração do capital: um estudo sobre a crise contemporânea. São Paulo: Ed. Xamã, 1996.

CARELLI, Rodrigo de Lacerda. Terceirização e intermediação de mão-de-obra: ruptura do sistema trabalhista, precarização do trabalho e exclusão social. Rio de Janeiro: Ed. Renovar, 2003.

Terceirização e intermediação de mão-de-obra na administração públicạ. In: SEMINÂRIO DE INTEGRAÇÃO DO MINISTÉRIO PÚBLICO FEDERAL E MINISTERRIO PÚBLICO DO TRABALHO, Goiânia, 2002. 12 p. mimeo.

Terceirização e direitos trabalhistas no Brasil. In: DRUCK, Graça; FRANCO, Tânia (Org.) A perda da razão social do trabalho. São Paulo: Boitempo, 2007.

CAVALCANTE, Sávio. Sindicalismo e privatização das telecomunicações no Brasil. São Paulo: Expressão Popular, 2009.

. Tendências da configuração do trabalho no setor de telecomunicações no Brasil. Lutas Sociais, São Paulo, n.24, p.44-59, 2010.

CHESNAIS, François. A mundialização do capital. São Paulo: Xamã, 1996.

COLLI, Juliana. A trama da terceirização. Campinas: Unicamp, 2000.

CONCEIÇÃO, Jefferson José; LIMA, Claudia Rejane. Empresários e trabalhadores diante da regulamentacão da terceirização: é possível um acordo mínimo? In: DAU, Deterceirização: é possível um acordo mínimo? In: DAU, DeJefferson José da. (Org.) Terceirização no Brasil: do discurso da inovação à precarização do trabalho (atualização do debate e perspectivas). Sã̃o Paulo: Annablume, CUT, 2009. p.187-213.

DAU, Denise Motta; RODRIGUES, Iram Jácome; CONCEIÇÃO, Jefferson José da. (Org.) Terceirização no Brasil: do discurso da inovação à precarizacão do trabalho (atualizacãa do debate e perspectivas). São Paulo: Annablume, CUT, 2009

DELGADO, Mauricio J. Godinho. Direitos fundamentais na relação de trabalho. In: SILVA, Alessandro et al. (Org.) Direitos humanos: essência do direito do trabalho. São Paulo: LTr, 2007.

DIAS, Sabrina de O. M.; OLIVEIRA, R. G. Depois da terceirização, a desterceirizacão: comparacão dos processos na CSN e na Caixa. In: CONGRESSO BRASILEIRO DE SOCIOLOGIA,15, 2011. Disponível em: www.sistemasmart.com.br/ sbs2011/arquivos/ 30_6_2011_23_17_21.pdf, 2011. Acesso em: 03 ago. 2011
DRUCK, Graça. Terceirização: (des)fordizando a fábrica; um estudo do complexo petroquímico. São Paulo: Boitempo, 1999.

O avanço da terceirização do trabalho: principais tendências nos últimos 20 anos no. Bahia: Análise \& Dados, Salvador, SEI, v.21, n.2, abr./jun., p.399-416, 2011.

; FRANCO, Tânia (Org.) A perda da razão social do trabalho. São Paulo: Boitempo, 2007.

DUMÉNIL, Gérard; LÉVY, Dominique. O imperialismo na era neoliberal. Crítica Marxista. Rio de Janeiro, n.18, p.11-36, 2004.

GODINHO, Luiz Flávio. Um mosaico de classe: a terceirização na Refinaria Landulfo Alves. 2003. 180 f. Dissertação (Mestrado) - Programa de Pós-Graduação em Ciências Sociais, Universidade Federal da Bahia. Salvador: 2003.

FARIA, Aparecid. Terceirizacão. Um desafio para o movimento sindical. In: RAMALHO, José R. ; Martins, Heloisa (Org.) Terceirização: negociação e diversidade no mundo do trabalho. São Paulo: Hucitec, 1994.

HIRATA, Helena (Org.) Sobre o "modelo" japonês: automatização, novas formas de organização e de relações de trabalho. São Paulo: Edusp, 1993.

JINKINGS, Isabela; AMORIM, Elaine Regina Aguiar. Produção e desregulamentação na indústria têxtil e de confecção. In: ANTUNES, Ricardo (Org.) Riqueza e miséria do trabalho no Brasil. Rio de Janeiro: Boitempo, 2006. p.337-385.

KLEIN, Naomi. Sem logo. São Paulo: Boitempo, 2006.

KREIN, José Dari. Tendências recentes nas relações de emprego no Brasil. 1990-2005. Campinas. 2007, 319 f. Tese (Doutorado em Economia Aplicada) - Universidade Estadual de Campinas. São Paulo, 2007.

LEIRIA, Jerônimo Souto; SARATT, Newton. Terceirizaçấo: uma alternativa de flexibilidade empresarial. São Paulo: Gente, 1995.

SOUTO, Carlos Fernando; SARATT, Newton Dornelles. Terceirização passo a passo: o caminho para a administração pública e privada. Porto Alegre: Ed. SAGRADC Luzzatto, 1992.

LEITE, Márcia de Paula. O futuro do trabalho: novas tecnologias e subjetividade operária. São Paulo. Scritta, 1994.

LIMA, Jacob Carlos. A terceirização e seus espaços: os territórios da precariedade - a experiência da indústria de confecção e calçados. In: DAU, Denise Motta; RODRIGUES Iram Jácome; CONCEICÃO, Jefferson José da. (Org.) Terceirização no Brasil: do discurso da inovação à precarização do trabalho (atualização do debate e perspectivas). São Paulo: Annablume, CUT, 2009. p.69-84.

MARCELINO, Paula. A logística da precarização. São Paulo: Expressão Popular, 2004.

Afinal, o que é terceirizacão? Em busca de ferramentas de análise e de ação política. Pegada, v.8, n.2, p.55-70, 2007.

Terceirização e ação sindical: a singularidade da reestruturação do capital no Brasil. 2008. 373 f. Tese (Doutorado em Ciências Sociais) - Universidade Estadual de Campinas.São Paulo, 2008.

Base fragmentada, ação combativa: a experiência sindical dos trabalhadores terceirizados da refinaria de Paulínia. In: BOITO JR. Armando; GALVÃ̃, Andréia. Política e classes sociais no Brasil dos anos 2000. São Paulo: Ed. Alameda, 2012. p.227-279.

MARTINS, Heloísa Helena Teixeira de Souza; RAMALHO, José Ricardo (Org.) Terceirização: diversidade e negociação no mundo do trabalho. São Paulo: Ed. Hucitec, CEDI/ NETS, 1994. 
MARTINS, Sérgio Pinto. A terceirização e o direito do trabalho. São Paulo: Atlas, 2005.

MORIN, Marie-Laure. Sous-traitance et relations salariales. Aspects de droit du travail. Travail et Emploi, Paris, n.60, p.23-43, 1994.

OLIVEIRA, Marco A. Terceirização: estruturas e processos em cheque nas empresas. São Paulo: Nobel, 1994.

PIORE, Michael J.; SABEL, Charles F. The second industrial divide: possibilities for prosperity. New York: Basic Books, 1984.

POCHMANN, Márcio. Sindeepres 15 anos: a superterceirização dos contratos de trabalho. Disponível em: www.sindeepres.org.br/ v01/index/Pesquisa\%20 Marcio\%20Pochman. pdf. 2007. Acesso em: 29 jul. 2007.

RAMALHO, José Ricardo; RODRIGUES, Iram Jácome. Trabalho, flexibilidade e terceirização: o caso da indústria automotiva. In: DAU, Denise Motta; RODRIGUES, Iram Jácome; CONCEIÇÃO, Jefferson José da. (Org.) Terceirização no Brasil: do discurso da inovação à precarização do trabalho (atualização do debate e perspectivas). São Paulo: Ed. Annablume, CUT, 2009. p. 85-99.
RUDUIT-GARCIA, Sandro. Relações interfirmas e emprego na rede de empresas: a experiência de externalização de uma empresa no setor de telecomunicações. Sociologias, Porto Alegre, UFRGS, v.4, n. 8, 2002.

Subcontratação. Terceirização. In: CATTANI, A. Davi; HOLZMANN, Lorena. Dicionário de trabalho e tecnologia. Porto Alegre: Ed. da UFRGS, 2006, p.274-276, 311-314.

SILVA, Carlos. Terceirização e trabalho informal. In: DAU, Denise Motta; RODRIGUES, Iram Jácome; CONCEIÇÃO, Jefferson José da. (Org.) Terceirização no Brasil: do discurso da inovação à precarização do trabalho (atualização do debate e perspectivas). São Paulo: Ed. Annablume, CUT, 2009. p.29-48.

TEIXEIRA, Francisco José Soares; OLIVEIRA, Manfredo Araújo de. (Org.) Neoliberalismo e reestruturação produtiva: as novas determinações do mundo do trabalho. São Paulo: Cortez; Fortaleza: Universidade Estadual do Ceará, 1998. 


\section{FOR A DEFINITION OF OUTSOURCING}

\author{
Paula Marcelino \\ Sávio Cavalcante
}

The reader of this paper will find a proposal for a definition of outsourcing that intends to be both analytically rigorous and politically useful. We argue that outsourcing is the workers' hiring process that is done through interposed company, whose ultimate objective is to reduce costs in relation to workforce and/or 'externalize' workers' conflicts. Although this formulation seems simple, and in fact it is, it is not consensual. As indicated in this paper, outsourcing is an object of study of several disciplines and there are many controversies concerning its definition within each one. This text is the result of extensive literature research and case studies carried out by the authors throughout their postgraduate studies.

KEY WORDS: outsourcing, subcontracting, labor.

\section{POUR UNE DÉFINITION DE LA SOUS- TRAITANCE}

\author{
Paula Marcelino \\ Sávio Cavalcante
}

L'objectif principal de ce texte est de proposer une définition de la sous-traitance qui soit à la fois rigoureuse d'un point de vue analytique et utile d'un point de vue politique. Nous affirmons que la sous-traitance est tout processus d'embauche de travailleurs par entreprise interposée dont le but essentiel est réduire les coûts de la main-d'oeuvre et/ou les conflits liés aux droits du travail. Si la formule semble être et est simple, elle n'est consensuelle. Comme nous le verrons dans ce texte, la sous-traitance est étudiée dans diverses disciplines mais, dans chacune d'elles, les controverses au tour de as définition sont nombreuses. Cette étude est résultat d'une ample recherche bibliographique ainsi que d'études de cas spécifiques réalisées par les auteurs dans leur travail de master et doctorat.

MOTS-CLÉS: sous-traitance, sous-contrat, travail.

Paula Marcelino - Doutora em Ciências Sociais. Professora do Departamento de Sociologia da Universidade de São Paulo (USP). Trabalha com temas relacionados à situação e à ação dos trabalhadores: crise e recuperação do sindicalismo, classes sociais, reestruturação produtiva, neoliberalismo e precarização do trabalho. Publicações recentes: Novo operariado, velhos desafios: o sindicalismo dos trabalhadores terceirizados. Estudos de Sociologia, 2011; Decline in Unionism? An Analysis of the New Wave of Strikes in Brazil. Latin American Perspectives, 2011; As palavras e as coisas: uma nota sobre a terminologia dos estudos de trabalho. Revista Mediações (UEL), 2011; A Logística da Precarização: terceirização do trabalho na Honda do Brasil, São Paulo: Expressão Popular, 2004 (com $1^{\mathrm{a}}$ reimpressão em 2009).

Sávio Cavalcante - Doutor em Sociologia pela Universidade Estadual de Campinas (IFCH/Unicamp). Atua nas áreas de sociologia e ciência política, especialmente nos temas relativos a trabalho, sindicalismo e classes sociais. Publicações recentes: As telecomunicações após uma década da privatização: a face oculta do sucesso. Eptic (UFS), 2011; Tendências da configuração do trabalho no setor de telecomunicações no Brasil. Lutas Sociais (PUCSP), 2010; Notas sobre uma polêmica na definição marxista do proletariado. Crítica Marxista (São Paulo), 2009. 